\title{
Developing Intelligent Child Protection and Security Systems
}

\author{
*Dr. Urmila A.Patil, "Rajashree D.Patil \\ *Professor, "Student, Dr. D. Y. Patil institute of technology Pimpri, Pune, India, \\ *urmilaapatil76@gmail.com, \#rajashree.j2201@gmail.com
}

\begin{abstract}
In present time, the security and safety aspect of a school going children is of main concern and paramount importance. In India, many children are found to be missing and yield to road accidents because of lack of preventive safety measures. Parents are always concerned about their children during commute. This project proposes an Raspberry pi based intelligent solution to assist parents in real time to track their children location. In order to track the location and find the identity of the child a AI thinker and camera is used in the proposed system. The system uses Raspberry pi as main microcontroller. The project also proposes safety systems such as person identification, Geofacing and automatically ON and OFF system using thumb impression. The working prototype model of the developed system exhibits good accuracy with reduced computational time. By incorporating all those above features, we can assure the safety and security of every school children.
\end{abstract}

Keywords-AI thinker, Geo-facing, intelligent system, Raspberry pi, security, safety, tacking.

\section{INTRODUCTION}

Children are named the "Supreme National Property" according to the National Children's Policy 1974[1]. We are the cornerstone upon which to build the future of a powerful and prosperous India. Especially in India, the rate of crime against children has increased over the years. Both the parents work these days, and are unable to monitor and keep track of their children's various activities. Therefore, on their return from school, children may be abducted and exposed to crimes such as kidnapping, slavery, child labor; sexual violence, etc. Among the reported cases, 300,000 Indian women and 64,000 girls have been abducted during the last nine years. Every year, the number of women kidnapping cases has risen by about 11.73 percent [2]. Also, girl child kidnappings jumped 23.2 percent each year, according to National Crime Statistics Bureau statistics. Nearly 85 per cent of all the country's kidnappings are of minor children, as reported by the crime bureau [4].

Now smartphones are the user's basic need now, these devices, offering tons of features that make our life so easy and convenient. This paper is tailored to children's safety. Today child safety is a major issue worldwide as child abuse is growing rapidly throughout the world in this paper we addressed how a Smartphone provides parents with surveillance and tracking so that they can easily track their children according to their needs. This proposed application implements the basic techniques needed below on the Android platform for this application: (a) Geo-Fencing

(b) Location tracking using AI thinker

(c) Messaging Service using AI thinker

(d) Face reorganization

GPS is helpful for child identification and also provides information about where the infant is actually located as well as the parents thereof. SMS systems that are used while smart phones do not allow internet connectivity in this case child may send a text message or exact location to parent. We also use speech to text conversion technique to send emergency message to parents when child is in danger situation. This system will help parents monitor their children's position without notifying them, as their movement is reflected on the parent mobile through Google maps. This framework is also helpful to girls who mostly research or do a job from far away from home. They will send their current location via SMS or miscall in danger situation to their parents in case of any emergency.

\section{A.TARGET USER}

The framework would be aimed at the age group of 4 to 12 years for middle class parent with kids.

\section{B. PLATFORM}

The android app will be running on the IoT platform and is used by various mobile devices for GPS monitoring. The GPS is responsible for keeping track of the device's location and reacting to the device's alert. Whereas GPS is used with the help of the cellular network to locate the device. The 
device's mobile app tracks the child's location in the online app using the GPS and GSM technologies. The parent is able to change the level of position alerts that suits their needs.

\section{PROBLEM STATEMENT}

Missing children problem has triggered numerous problems around the world following the 2007 Nurlin Jazlin murder. The missing case, however, is still prevalence, particularly in India, with the highest number of children missing. There are a total number of 2015 children reported missing in 2014, 1782 cases recorded in 2015 and 140 cases reported on January of this year alone. These figures showed the severity of missing cases in India that need parent questions about the cases. It's hard for the parent to keep a watch on their child without using technology, particularly when the child is outdoors. The parent can't even stop the mistake we'll be making in the future. The evaluation may suggest that the parent is distracted on their smart phones nowadays, which can lead them to forget their child for a couple of seconds or even minutes, which could put 3 of their child at risk of missing in just a few seconds. A solution is needed for the parent to keep track of the whereabouts of their child when the child is not beside them and get informed when their child reaches or leaves a certain destination.

The emerging technologies had also allowed us to keep tracking our child via sound recording or even CCTV. However, each of them has its own drawbacks and disadvantages, for instance CCTV can only use the camera to supervise the infant and can only use it indoors but not outdoors. We can't monitor the child when they're outside of the vision of CCTV; the sound recorder can only be used to capture the sound, so we can't know their real-time position and the direction they've been, which was unworkable.

A new approach is needed to solve the current constraint of using those technology to track the infant. Furthermore, although an existing child tracking system has been sold online but based on observations of the use of technological apps by parents, most parents do not receive a greeting address from the child tracking system. Even before the commercial releases information about the child tracking system. That's the explanation the parent's only minority know about the system's existence. There is only a limited choice of the based on my analysis through the official and unofficial sales website. Many of the system operates only for a single region, and does not fulfill the parent's criteria for the software.

And if it's affordable, most smartphones need to be imported and the price is in US dollar or Euro, which was very expensive when translated to INR, but the mobile option can be a safer alternative for parents to track their infant. Smartphone has been a tool for everyone since lately. Smartphone can do about anything from calling to surveillance, and most kids get their first smartphone because they're little and the parent doesn't need to buy extra tracking device just to watch their children. According to the study, 58 per cent of children own the mobile in the age group from the ages of 1 and 12 .

In addition, in today's technological era, smartphones only 4 allowed children to reach the classroom in some of our country's country and international schools due to their incredible mobility and internet capabilities that enabled them to access and search for more online information.) We've seen the potential of smartphones, so that's why there's a need to evaluate the current approach on the specific framework so increase the parent's demand for the product to incorporate the necessary features into the app to fulfill their requirements.

\section{PROJECT SCOPE}

This project would consist of the construction of an efficient and marketable framework in which the product architecture and functionality will be tested on the basis of the survey results. The description below describes the intended customer, platform, general functionality, which will include the project's workflow, which vice versa.

\section{A.EXISTING CHILD TRACKING SYSTEM}

Various kinds of child monitoring program have been introduced in most of the world. The work was conducted to examine the different business model offered by the specific device First of all, all trackers will provide real-time information about the child's location. This function is necessary to ensure that the parent can see the location of their child in real time as needed, with the exception of GPS smart soles, most of them have the emergency button. Emergency button is a type of button that is mounted on the tracker for the child to press during an emergency. Based on the sensor used, the specific behavior will get activated.

\section{METHODOLOGY}

\section{A.DESIGN SYSTEM}

Both children may be fragile because of their early age and ability to develop. We can be 'open to' hurt, illness, harassment and aggression. Kids can also be vulnerable to adverse effects and 'at risk' behaviour, due to various conditions and/or causes. In fact, marginalisation exacerbates weakness. The burden of risk and insecurity in development settings such as India falls heavily upon youth. The effect of infant deprivation and marginalization can be short or long lasting based on the scale, existence, magnitude, and other factors involved. The loss, too, may be lasting. The impact will be on the child's physical, financial, social, psychological and mental health and welfare. Our designed system explained below: 
We build system for providing safety to children. System consists of a AI thinker that is combination of GSM and GPS. Raspberry pi used as main controller. In existing system we enhance the Geo-fencing using such system we can fix boundaries when child will exceed the boundary parents get alert via miscall or SMS and buzzer gets ON and using same we can calculate distance of child from home. We also use speech to text conversion for child safety. Whenever child is at home system gets automatically OFF and gets ON using thumb impression. Our system really helpful for children and parent. Figure 2 shows block diagram of child safety system.

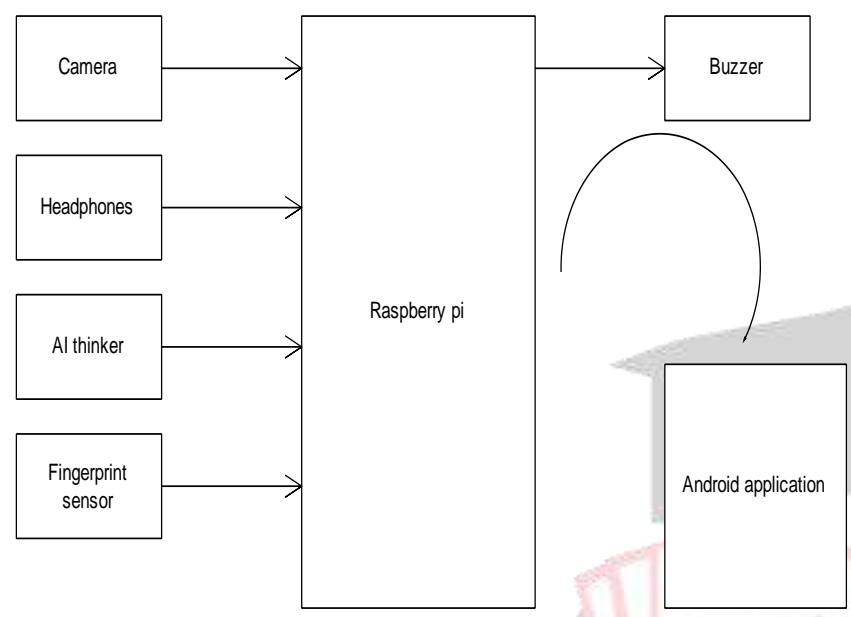

Fig.1.Block diagram of child safety system

Fig.1.Block diagram of child safety system

\section{A. Application development}

In developing this application for parents, we required GPS enable smart phones which are used to track the child's location and for developing android based applications, we required Android SDK tools which support android application development. The reason for selecting android operating system is that now days millions of users are using smart phones. The solution for tracking and a missing child is done with the help of GPS and GSM technologies. There are two main services are used for this application that is GPS and SMS. For location services is GPS and telephony services is SMS.

Generally the selected operating system is android to over all the features. SMS and miscall is used for communicating between child side and parent side. The application developed to make a user-friendly approach on both sides, we require android IDE. The architecture of the application is shown in figure. 3

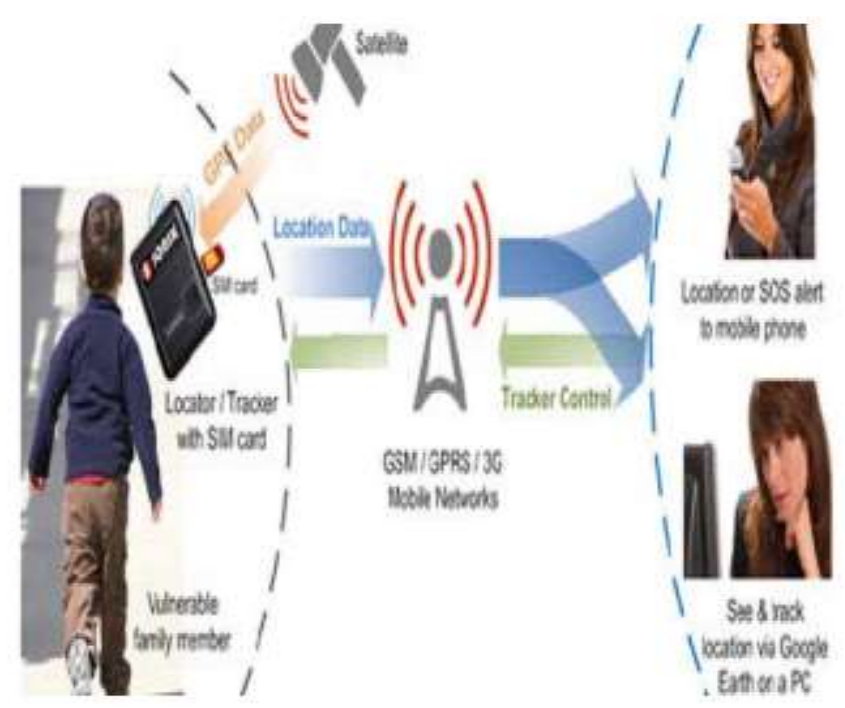

Fig.2. Architecture of Application

\section{OTHER SPECIFICATION}

A. Advantages

Low cost

Low maintenance

Easy to run

No need for consultants

Children can manage easily

\section{B. Applications}

Children safety purpose

Suitable for Girls who arrive late at home

It can be used for women safety

\section{Limitation}

There are some drawbacks to the design.

1. The project will rely in large part on the devices ' GPS and network connectivity. If the computer has a GPS error, or the network link fails, the machine does not operate as planned.

\section{Future scope}

1. Improves the geofening experience by developing your own geofening API using suitable algorithms that allow the parent to have different ways of constructing geofence instead of only drawing a geofence circle.

2. Improves the knowledge of route history by building its own algorithm for estimating and maximizing the location estimate to solve the problem of fluttering movement while the child is at the same spot.

3. To those who subscribe to the program will be included the community tracking feature where the parent will share 
the tracker with the predefined trustworthy community to better protect their child in the future.

\section{RESULTS}

Child Security is any intervention or program that tackles or protects children from abuse, coercive, neglect and exploitative circumstances. It applies to shielding children from or against any danger / risk perceived or actual. In dangerous conditions it helps to reduce their vulnerability. Our system work properly as per our aim. Figure 3(a) shows the face recognition here we use face of one of my friend to prove system work accurately .Figure 3(b) address that output from AI-thinker which is text message to stored contact numbers. Figure 3(c) shows the coding of our system.

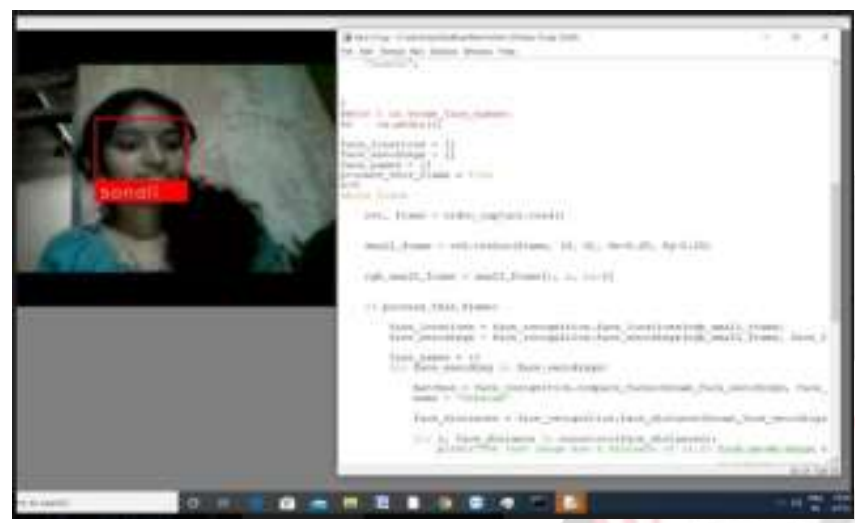

(a)

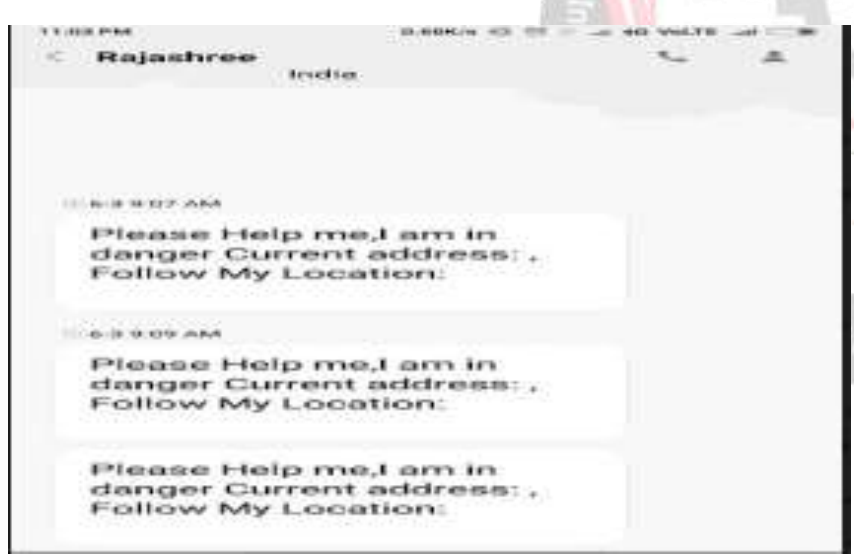

(b)

Fig.3. Results of design system

\section{CONCLUSION}

In conclusion, the aim of this project is to find the missing children and to ensure child safety. Our system fulfill the objective such as provide the child safety. This system helps to find missing children. The approach presented in this paper takes advantage of the smart framework that provides rich features such as Google maps, GPS, SMS etc. Many of the best works applied in the past are focused on SMSbased tracking, which is not helpful in having an precise position in our proposed system. Further strengthen the framework; we have added Geo-fencing and Emergency Messaging systems.

\section{REFERENCES}

[1] Akira Suyama and Ushio Inoue, "Using Geofencing for a Disaster Information System" Computer and Information Science (ICIS), 2016 IEEE/ACIS 15th International Conference, August 2016

[2]Perappadan, Bindu Shajan, "22 Children Go Missing in Delhi Every Day”, The Hindu, Web, May 2016.

[3] Bhatnagar, Gaurav Vivek, "70 per Cent of Road Accidents in India Due to Drunken Driving", The Hindu, Web, May 2016.

[4] Press Trust of India, "10-year-old Boy Crushed under the Wheels of School Bus", Business Standard, Web, Aug 2015.

[5] A.Subburaj, "Coimbatore twin murder", The Times of India, Web, Nov 2010.

[6] Ratnaprabha Kasde and G. Gugapriya, "Accident Avoidance System using CAN," in Indian Journal of Science and Technology, vol. 9(30): pages 1-8, Aug 2016.

[7] K. Vidyasagar, G. Balaji, and K. Narendra Reddy, “ RFID-GSM imparted School children Security System," in Communications on Applied Electronics, Vol 2( 2): pages 17-21, June 2015.

[8] "Naziha fell asleep in Abu Dhabi school bus; Locked in, forotten. Hours later 4-year-old was dead". Available at : http://www.emirates247.com/news/naziha-fell-asleep-inabu-dhabischool-bus-locked-in-forgotten-hours-later-4year-old-was-dead-2014- 10-08-1.565435. [Accessed: 25 February 2016]

[9] "Youth hijacks school van in Assam, abducts girl". Available at: http://www.newindianexpress.com/nation/Youth-HijacksSchool-Vanin-Assam-Abducts-

Girl/2013/12/04/article1927860.ece. [Accessed:

February 2016]

[10] Anwaar Al-Lawati, Shaikha Al-Jahdhami, Asma AlBelushi, Dalal AlAdawi, Medhat Awadalla and Dawood AlAbri, "RFID-based system for school chilldren transportation safety enahcement," Proceedings of the 8th IEEE GCC Conference and Exhibition, Muscat, Oman, 1-4 February, 2015. 